\title{
Contents, Vol. 45, 1983
}

\section{No. 1 Original Paper}

Malignant Tumours of the Nasal Cavity and Paranasal Sinuses

Lund, V.J 1

Acute Epiglottitis. A Management Protocol Based on a 15-Year Material

Andreassen, U.K.; Hancke, A.B.; Leth, N.K.; Husum, B.; Tos, M 13

Ceruminous Glands in Otosclerosis. A Histopathological and Histochemical Study

Talaat, M.; Gafaar, H.; Talaat, A.M.; Elwany, S 20

Ultrastructural Organization of the Round Window Membrane in the Infant Human Middle

Ear

Miriszlai, E.; Benedeczky, I.; Horváth, K.; Köllner, P

Influence of Adaptation upon the Impulsive Time Constant of the Human Vestibulo-Ocular Reflex System. I. Theoretical Study

Boumans, L.J.J.M.; Rodenburg, M.; Maas, A.J.J 39

Influence of Adaptation upon the Impulsive Time Constant of the Human Vestibulo-Ocular Reflex System. II. Experimental Investigation

Boumans, L.J.J.M.; Rodenburg, M.; Maas, A.J.J 52

Book Reviews $\quad 60$

No. 2 Original Paper

Frequency Response of the Human Vestibulo-Ocular Reflex System at Low Frequencies:

The Effect of Adaptation. I. Theoretical Study

Boumans, L.J.J.M.; Rodenburg, M.; Maas, A.J.J

Frequency Response of the Human Vestibulo-Ocular Reflex System at Low Frequencies:

The Effect of Adaptation. II. Experimental Investigation

Boumans, L.J.J.M.; Rodenburg, M.; Maas, A.J.J 72

Effect of Tubal Occlusion on Bone Formation in the Middle Ear of the Rat

Beek, J.M.H. van der; Broek, P. van den; Kuijpers, W

A Mixed Tumor of the Skin of the Nose

Manni, H.J.; Raalte, J.A. van 96

Red Blood Cell, Serum and Tissue Magnesium Levels in Subjects with Laryngeal Carcinoma

Szmeja, Z.; Kończewska, H 102

A Newly Devised Speech Accumulator

Ryu, S.; Komiyama, S.; Kannae, S.; Watanabe, H 108

Book Reviews $\quad 115$

Announcements $\quad 116$

IV

Contents

No. 3 Original Paper

Response of the Human Vestibulo-Ocular Reflex System to Constant Angular Acceleration. I. Theoretical Study 
Boumans, L.J.J.M.; Rodenburg, M.; Maas, A.JJ

Response of the Human Vestibulo-Ocular Reflex System to Constant Angular Acceleration.

II. Experimental Investigation

Boumans, L.J.J.M.; Rodenburg, M.; Maas, A.JJ 130

Chronological Changes of Electrocochleogram in Experimental Endolymphatic Hydrops.

Special Reference with AP Output Potential and Hair Cell Cilia

Kumagami, H.; Miyazaki, M 143

Prognosis and Pathogenesis of Sudden Deafness with Scaling Out

Yanagita, N.; Suzuki, Y.; Murahashi, K.; Miyake, H154

Collagenase Activity in Cholesteatoma

Iwanaga, M.; Yamamoto, E 166

Book Review 176

No. 4 Original Paper

Significance of High Percentages of S-Phase Cells in Human Pituitary Tumours

Anniko, M.; Tribukait, B.; Wersäll, J 177

Rhinitis medicamentosa. An Experimental Histopathological and Histochemical Study

Elwany, S.S.; Stephanos, W.M

187

Generation Mechanism of the Negative Endocochlear Potential during Early Stage of Anoxia

Kusakari, J.; Rokugo, M.; Kambayashi, J.; Arakawa, E.; Ohyama, K.; Hara, A.; Kawa

moto, K 195

Otoneurological Test Results Analyzed by Means of a Quantitative Statistical Method

Imoto, T.; Nakai, Y 203

Vestibular Neurectomy for Dizziness after Head Trauma. A Review of 28 Patients

Sanna, M.; Ylikosky, J 216

Changes in Point Prevalence of Secretory Otitis in Preschool Children

Tos, M.; Holm-Jensen, S.; Stangerup, S.-E.; Sørensen, C.H 226

Book Reviews 235

Announcement 236

No. 5 Original Paper

Rhinosporidiosis in The Netherlands. A Case Report Including Ultramicroscopic Features

Prins, L.C.; Tange, R.A.; Dingemans, K.P 237

Biological Behaviour of Laryngeal Adenoid Cystic Carcinoma. Therapeutic Consider

ations

Ferlito, A.; Caruso, G 245

cü-Diamminedichloroplatinum: A Cytostatic with a Ototoxic Effect

Hartwig, S.; Pettersson, U.; Stable, J 257

Impairment of Visuo-Vestibular Interaction in Humans Exposed to Toluene

Hydén, D.; Larsby, B.; Andersson, H.; Ödkvist, L.M.; Liedgren, S.R.C.; Tham, R. . 262

Internal and External Vestibular Caloric Tests in Pigeons. A Nystagmographic Study

Gursel, A.O.; Jong, H.A.A. de; Oosterveld, W.J 270

Tuohimaa/Aantaa/Toukoniitty/Mäkelä

Plate I 


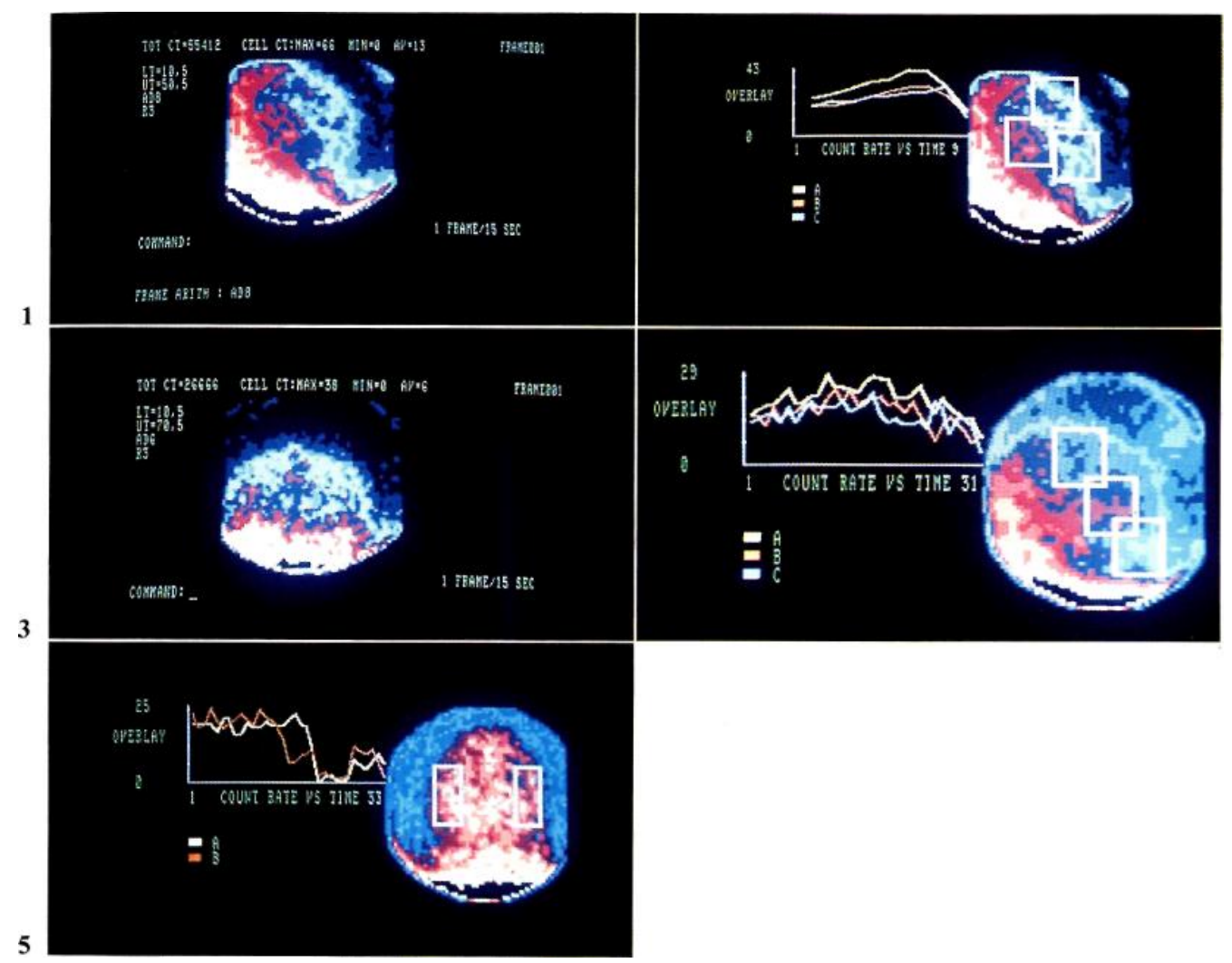

Fig. 1. PET during normal caloric reaction. Right lateral view. The yellow on the left is part of the respiratory system (nose and mouth).

Fig. 2. As in figure 1. Normal caloric reaction, count rate calculated on identical areas. $A=$ Yellow line is the temporoparietal area; $\mathrm{B}=$ temporal area; $\mathrm{C}=$ parietal area.

Fig. 3. A-p projection after right ear caloric stimulation. Higher count rate is calculated on the left temporoparietal cortex.

Fig. 4. Right lateral view during caloric stimulation. Yellow line showing count rate on the temporoparietal cortex.

Fig. 5. A-p projection during caloric reaction. Yellow line indicates count rate on the left temporoparietal area. Note how the ocular fixation decreases the count rate.

ORL, Vol. 45 S. Karger, Basel

Contents V

Analysis of Righting Reflex in Cats with Unilateral and Bilateral Labyrinthectomy

Igarashi, M.; Guitierrez, 0279

Postoperative Aural Attico-Antroscopy for Cholesteatoma

Kanzaki, J 290

Announcements 244

No. 6 Original Paper

Effect of Amphetamine on Optokinetically Evoked Head and Eye Movements in the Squirrel Monkey

Isago, H.; Igarashi, M.; O-Uchi, T.; Wright, W.K.; Homick, J.L 297

Differential Diagnosis of Central Vestibular Disorders by Combined Tests with Perrotatory

Ocular Fixation and Auditory Brain Stem Response

Kanzaki, J.; O-Uchi, T 306 
Studies of Vestibular Cortical Areas with Short-Living $15 \theta 2$ Isotopes

(With 1 color plate)

Tuohimaa, P.; Aantaa, E.; Toukoniitty, K.; Mäkelä, P

Electrocochleography: Using Extratympanic or Transtympanic Methods?

Probst, R 322

Stapedectomy in Osteogenesis imperfecta

Pedersen, U.; Elbrønd, 0

330

Microlaryngoscopy in Local Anesthesia Using Brünings' Counterpressor

Minnigerode, B $\quad 338$

Book Review $\quad 347$

Announcement

347

Author Index

348

Subject Index

349 